\title{
Intense schooling linked to myopia
}

\author{
Education systems must change to protect children's vision
}

\author{
Ian G Morgan professor ${ }^{1}$, Amanda N French lecturer ${ }^{2}$, Kathryn A Rose professor ${ }^{2}$
}

${ }^{1}$ Research School of Biology, Australian National University, Canberra, ACT 2601, Australia; ${ }^{2}$ Discipline of Orthoptics, Graduate School of Health, University of Technology Sydney, Ultimo, NSW, Australia

In a linked article, Mountjoy and colleagues (doi:10.1136/bmj. $\mathrm{k} 2022$ ) provide compelling evidence that increased education causes myopia- a matter of sometimes acrimonious controversy for more than 400 years. ${ }^{1}$ The authors used the UK Biobank sample (www.ukbiobank.ac.uk) to perform an elegant bidirectional mendelian randomisation study, using genetic variants associated with myopia ${ }^{2}$ and with years of education. ${ }^{3}$

The logic of mendelian randomisation is simple. Genetic variants are inherited largely independently of potentially confounding variables. Thus, in relation to education and myopia it is possible to ask, with minimal confounding, whether genetic variants associated with myopia lead to more years of education or whether those associated with more education lead to more myopia. The results strongly favoured the second hypothesis.

Many other lines of evidence support a causal role for education. ${ }^{4}$ As societies have developed formal education systems, the prevalence of myopia has increased from around $1 \%$ to as much as $80-90 \%$ in young adults. ${ }^{5}$ Rapid increases in the prevalence of myopia have been associated with rapid changes in access to education (in East Asia after the second world war, and rapidly in China at the end of the cultural revolution).

In addition, boys from Orthodox Jewish families in Israel receive intensive religious education and are much more myopic than their sisters, who receive much less intensive education, and those who receive secular education. ${ }^{6}$ These large scale social changes are similar to non-randomised intervention trials. What they lack is randomisation - the gap filled by Mountjoy and colleagues' study.

It is important to be clear about what this study does not mean. It does not restore the once dominant idea that myopia is totally under genetic control; derived from the high concordance and heritability of refraction in twin studies. ${ }^{7}$ Nor does it suggest that years of education is under strong genetic control. In both cases, the genetic contribution to phenotypic variance is small: $4.32 \%$ for myopia and $0.71 \%$ for years of education in the current analysis. The small effect of genes on years of education is reflected by variation in myopia, but there is plenty of room for environmental and social factors to have major effects on myopia, as the evidence suggests. ${ }^{1}$

Some quantitative aspects of the results may not generalise to other parts of the world. For example, the observational analysis suggests that every additional year of education results in -0.18 dioptres more myopia, whereas the mendelian randomisation analysis suggests a stronger -0.27 dioptres/year. In comparison, the younger generation in Chinese cities is close to -2.00 dioptres more myopic than their parents. ${ }^{8}$ But they do not, on average, have eight or more additional years of education; on average they have only two or three. What has happened in East Asia is much more than just increased years of schooling.

As noted by the authors, there has been a trend to increasingly early onset of myopia in the school years in East Asia. ${ }^{5}$ This is probably due to early intense educational pressures such as homework at preschool level, combined with little time for play outdoors. As a result, almost $50 \%$ of children in East Asia are now myopic by the end of primary school, compared with less than $10 \%$ in the British ALSPAC study. ${ }^{9}$ Early onset allows more time for myopia to progress to high and potentially pathological myopia, and this is probably the major concern with the myopia epidemic. Fortunately, prevention of both myopia onset and progression now seems possible.

The epidemiological evidence, even without this mendelian randomisation study, was so strong that school based myopia control began some years ago in East Asia. Increased time outdoors seems to slow the onset of myopia ${ }^{1011}$ and was adopted for school based control of myopia in Taiwan in 2010. School based myopia control has an even longer history in mainland China, although the eye exercises introduced more than 50 years ago have obviously not prevented an epidemic of myopia.

Fundamental reform of the East Asian schooling systems, characterised by early onset of educational pressures and streaming by performance, has not yet been attempted. Instead, the regular release of the international PISA (programme for international student assessment) surveys of educational outcomes (www.oced.org/pisa), with league tables dominated by the East Asian countries with epidemic levels of myopia, ${ }^{12}$ 
regularly leads to calls for other countries to emulate East Asian schooling.

In response, we need to remember that East Asian education systems have played a major role in producing the current epidemic of myopia and high myopia, and that these systems will require substantial change to help protect the vision of future generations.

Competing interests: We have read and understood the BMJ policy on declaration of interests and declare the following: IM has advised Novartis on the early development of a drug to prevent myopia.

Provenance and peer review: Commissioned; not peer reviewed.

1 Mountjoy E, Davies NM, Plotnikov D, etal . Education and myopia: assessing the direction of causality by mendelian randomisation. BMJ 2018;361:k2022.

2 Kiefer AK, Tung JY, Do CB, etal. Genome-wide analysis points to roles for extracellular matrix remodeling, the visual cycle, and neuronal development in myopia. PLoS Genet 2013;9:e1003299. 10.1371/journal.pgen.1003299 23468642

3 Okbay A, Beauchamp JP, Fontana MA, etal. LifeLines Cohort Study. Genome-wide association study identifies 74 loci associated with educational attainment. Nature 2016;533:539-42. 10.1038/nature17671 27225129
4 Morgan IG, French AN, Ashby RS, etal . The epidemics of myopia: Aetiology and prevention. Prog Retin Eye Res 2018;62:134-49. 10.1016/.jpreteyeres.2017.09.004 28951126

5 Lin LL, Shih YF, Hsiao CK, Chen CJ. Prevalence of myopia in Taiwanese schoolchildren: 1983 to 2000. Ann Acad Med Singapore 2004;33:27-33.15008558

6 Zylbermann R, Landau D, Berson D. The influence of study habits on myopia in Jewish teenagers. J Pediatr Ophthalmol Strabismus 1993;30:319-22.8254449

7 Sorsby A, Sheridan M, Leary GA. Refraction and its components in twins. Report Spec Rep Ser Med Res Counc (G B) 1962, Report No 303. HMSO, London.

8 Liang YB, Lin Z, Vasudevan B, etal. Generational difference of refractive error in the baseline study of the Beijing Myopia Progression Study. Br J Ophthalmol 2013;97:765-9. 10.1136/bjophthalmol-2012-302468 23590854

9 Guggenheim JA, Northstone K, McMahon G, etal . Time outdoors and physical activity as predictors of incident myopia in childhood: a prospective cohort study. Invest Ophthalmol Vis Sci 2012;53:2856-65. 10.1167/iovs.11-9091 22491403

$10 \mathrm{He} \mathrm{M}$, Xiang F, Zeng Y, etal . Effect of time spent outdoors on the development of myopia among children in China: a randomised clinical trial. JAMA 2015;314:1142-8. 10.1001/jama.2015.10803 26372583

11 Rose KA, Morgan IG, Ip J, etal . Outdoor activity reduces the prevalence of myopia in children. Ophthalmology 2008:115:1279-85. 10.1016/j.ophtha.2007.12.019 18294691

12 Morgan IG, Rose KA. Myopia and international educational performance. Ophthalmic Physiol Opt 2013;33:329-38. 10.1111/opo.12040 23662964

Published by the BMJ Publishing Group Limited. For permission to use (where not already granted under a licence) please go to http://group.bmj.com/group/rights-licensing/ permissions 